\title{
A new approach for the kinetic modeling of free radical bulk polymerization of styrene
}

\author{
Oskar Bera, Radmila Radičević, Dragoslav Stoiljković, Mirjana Jovičić and Jelena Pavličević
}

The kinetics of styrene-free radical bulk polymerization was studied by differential scanning calorimetry (DSC). The data obtained from DSC thermograms were used to model and predict the autoacceleration during styrene polymerization and to understand how it is influenced by temperature. The experimental data were well described by the estimated kinetic model. The model included two processes (the first-order reaction and autoacceleration), because they occur simultaneously as two parallel reactions rather than being strictly separated. It was found that the autoacceleration activation energy is approximately four times lower than the energy of the first-order reaction. In addition, the first-order reaction followed by the autoacceleration of the styrene-free radical bulk polymerization occurs simultaneously only between 41.7 and $110.5{ }^{\circ} \mathrm{C}$.

Polymer Journal (2011) 43, 826-831; doi:10.1038/pj.2011.76; published online 10 August 2011

Keywords: autoacceleration; differential scanning calorimetry; polymerization kinetics; polystyrene; styrene-free radical bulk polymerization

\section{INTRODUCTION}

It is well known that the free radical bulk polymerization of vinyl monomers (derivates of acrylic and methacrylic acids, vinyl acetate, styrene, ethylene and so on) is characterized by the autoacceleration phenomenon. ${ }^{1-3}$ The free radical polymerization of these monomers can be explained by classical theory up to definite conversion. After that conversion, autoacceleration of polymerization occurs. The onset of autoacceleration is the moment when the polymerization rate departs from the value anticipated by the classical theory of free radical polymerization..$^{3-7}$ The onset and the intensity of autoacceleration are determined by the type of monomer, initiator concentration, temperature and other reaction conditions.

Ebdon and $\mathrm{Hunt}^{3}$ used differential scanning calorimetry (DSC) to follow the course of free radical bulk polymerization of styrene and concluded that autoacceleration is less pronounced at $90^{\circ} \mathrm{C}$ than at $80^{\circ} \mathrm{C}$ and is absent at $100^{\circ} \mathrm{C}$ and above. Autoacceleration appeared at about $2 \%$ conversion of styrene polymerized at $20^{\circ} \mathrm{C}$ for 252 days in the presence of $2,2^{\prime}$-azobisisobutyronitrile. ${ }^{8}$ To explain this autoacceleration, an equation was applied to the kinetic data obtained under the condition of predominant transfer to the monomer. It was concluded that polymer molecules may move by repetition and the mobility of segments decreases with decrease of free volume. ${ }^{8}$ Comparisons of the results obtained for styrene-free radical bulk polymerization with model predictions have quantified the dependence of the gel effect strength on the predominance of chain transfer events. ${ }^{9}$ Cioffi et al. ${ }^{10}$ performed a rheokinetic study of the bulk-free radical polymerization of styrene with a helical barrel rheometer. The rheokinetic measurements show that autoacceleration in the free radical polymerization of styrene can be reduced when the polymer- ization is performed at a high screw rotational velocity. Simulation of styrene-free radical polymerization in batch reactors has been performed; ${ }^{11}$ the model predicts the monomer conversion, number and mass average molecular masses as a function of time. A comprehensive kinetic model was developed for the combined chemical and thermal-free radical polymerization of styrene to predict the styrene polymerization rate and molecular weight distribution of the polystyrene. $^{12}$ To determine the steady-state and dynamic behavior of a continuous process, a mathematical model for the free radical polymerization of styrene was developed. ${ }^{13}$

Many theories have been developed to explain the polymerization autoacceleration of styrene and other vinyl monomers. ${ }^{4,14-22}$ According to the origin and reason of the autoacceleration onset, they can be classified as follows: theory of gel effects, theory of entanglement, free volume theory, theory of impenetrable macromolecular coils, theory of polymerization of organized monomer systems and theory of microheterogeneous polymerization. These theories have been reviewed elsewhere. ${ }^{23}$

However, the existing theories have not been completely verified experimentally. Their main shortcoming is that they mainly take the onset of acceleration as a characteristic point in polymerization rate vs time curve. We have shown that there are some additional characteristic points in the case of methyl-, ethyl-, butyl- and dodecyl methacrylate polymerization: ${ }^{4,5,24}$ the maximum polymerization rate and the two inflection points before and after that maximum.

The aim of this work was to confirm the existence of these characteristic points and find a suitable mathematical model of the kinetics of styrene-free radical bulk polymerization. The data obtained from DSC thermograms were used to model and predict the 
autoacceleration during styrene polymerization and understand how it is influenced by temperature.

\section{MATERIALS AND METHODS}

\section{Chemicals}

- Styrene (Merck, Darmstadt, Germany) was freed of inhibitor before use. It was washed with $10 \%$ aqueous $\mathrm{NaOH}$ solution, dried over anhydrous $\mathrm{CaCl}_{2}$, and distilled under nitrogen and reduced pressure.

- Initiator: 2,2'-azobisisobutyronitrile (Merck), was recrystallized from methanol.

\section{Methods}

The bulk polymerization of styrene was performed using a DSC apparatus (TA Instruments, New Castle, DE, USA, Model Q20). Approximately $5 \mathrm{mg}$ of the monomer, containing $1 \mathrm{wt} \% 2,2^{\prime}$-azobisisobutyronitrile, was put into a hermetic aluminum DSC pan and sealed with a hermetic aluminum lid. Nitrogen was used as purge gas with a flow rate of $50 \mathrm{~cm}^{3} \mathrm{~min}^{-1}$. Polymerizations were performed under isothermal conditions at five different temperatures $(70,75,80$, 85 and $90^{\circ} \mathrm{C}$ ). The amount of polymerized monomer (proportional to the heat evolved during reaction) was calculated from the area between the isothermal DSC curve and the baseline, using the method described in the literature. ${ }^{20,25,26}$ The amount of unreacted monomer was determined by prolonging the polymerization in the dynamic thermal range, from the temperature of isothermal polymerization to $220^{\circ} \mathrm{C}$, at a heating rate of $10^{\circ} \mathrm{C} \mathrm{min}^{-1} .{ }^{20,25}$

\section{RESULTS AND DISCUSSION}

DSC thermograms of styrene-free radical bulk polymerizations at different temperatures are presented in Figure 1. Three characteristic points are clearly observed: the onset of acceleration (point $\mathrm{M}$ ), the maximum of the polymerization rate (point $S$ ) and the end of polymerization (point $\mathrm{K}$ ). ${ }^{4,5}$ Point $\mathrm{M}$ was determined as the minimum and point $\mathrm{S}$ as the maximum in the DSC curve. Point $\mathrm{K}$ was determined as the moment when the isothermal DSC curve became horizontal.

To find the monomer conversion degree, equation (1) was used:

$$
X=\frac{\int_{0}^{\tau}(\mathrm{d} H / \mathrm{d} \tau) \mathrm{d} \tau}{\int_{0}^{\tau_{\mathrm{K}}}(\mathrm{d} H / \mathrm{d} \tau) \mathrm{d} \tau+H_{\mathrm{D}}}
$$

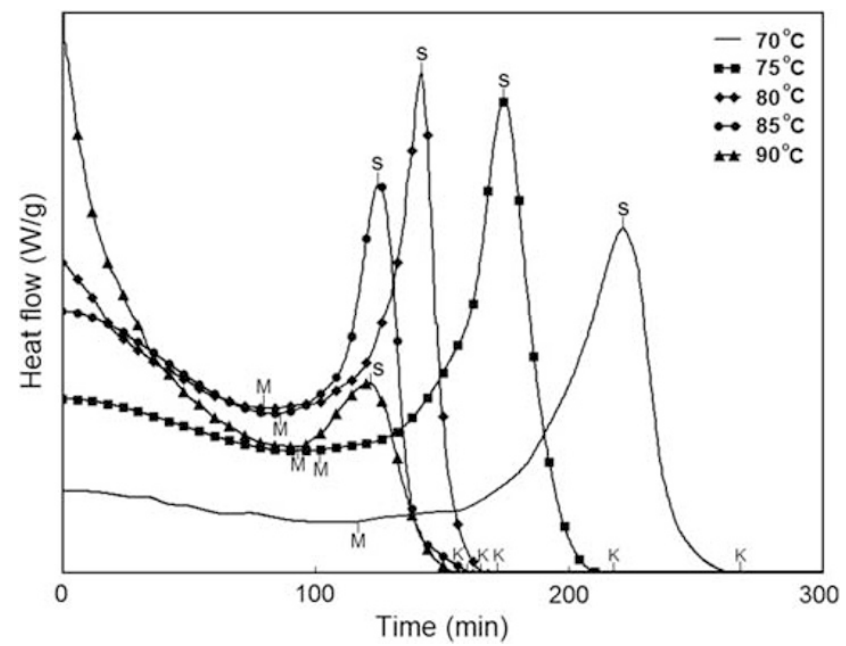

Figure 1 Differential scanning calorimetry (DSC) thermograms of styrene-free radical polymerization at different temperatures ( $1 \mathrm{wt} \% 2,2^{\prime}$ azobisisobutyronitrile). where $X$ is monomer conversion, $X=\left(C_{\mathrm{M} 0}-C_{\mathrm{M}}\right) / C_{\mathrm{M} 0} ; C_{\mathrm{M} 0}$ and $C_{\mathrm{M}}$ are initial monomer concentration and concentration at time $\tau$, respectively; $\mathrm{dH}$ is the reaction enthalpy for an infinitesimal polymerization time $\mathrm{d} \tau(\mathrm{min}) ; \tau_{\mathrm{K}}$ is the time necessary to achieve point $\mathrm{K}$; and $H_{\mathrm{D}}$ is the heat evolved from the polymerization of the unreacted monomer after point $\mathrm{K}$, assigned to the area under the dynamical DSC curve. The dependence of styrene conversion $X$ at different temperatures on the polymerization time is shown in Figure 2.

The conversion vs time curves of styrene polymerization contain a ' $\mathrm{S}$ ' shape part, which is characteristic of autoacceleration. The rate of polymerization $R_{\mathrm{pol}}=\mathrm{d} X / \mathrm{d} \tau$ is equal to the slope of the conversion vs time curve. Acceleration $\mathrm{d} R_{\mathrm{pol}} / \mathrm{d} \tau=\mathrm{d}^{2} X / \mathrm{d} \tau^{2}$ is equal to the slope of the $R_{\text {pol }}$ vs time curves (Figure 3 ). Styrene polymerization shows the same characteristic points as alkyl methacrylate polymerization: ${ }^{4,5}$ onset of autoacceleration $(\mathrm{M})$, maximum autoacceleration $(\mathrm{P})$ and maximum polymerization rate $(\mathrm{S})$, followed by a deceleration stage with minimum $(\mathrm{R})$ and final conversion $(\mathrm{K})$

The time and styrene conversions necessary to achieve the characteristic points are given in Table 1 . The conversion $X_{\mathrm{M}}$ at the onset of autoacceleration increases with increasing polymerization temperature, in accordance with published data. ${ }^{20,27}$

\section{Kinetic model}

It is necessary to find a kinetic model that fits the conversion vs time curves, and shows the same derivatives $(\mathrm{d} X / \mathrm{d} \tau)$ and $\left(\mathrm{d}^{2} X / \mathrm{d} \tau^{2}\right)$ as the experimental results (Figure 3).

From Figure 2, it can be seen that the polymerization process consists of three parts: up to point $\mathrm{M}$, autoacceleration from point $\mathrm{M}$ to point $S$ and deceleration from point $S$ to point $\mathrm{K}$.

The first part of a conversion vs time curve can be explained by classical free-radical polymerization. Hence, the polymerization rate $R_{\text {pol }}$ in that part can be expressed by equation (2). The reaction rate is first order to the monomer and one-half order to the initiator concentration.

$$
\begin{aligned}
R_{\mathrm{pol}} & =\frac{-\mathrm{d} C_{\mathrm{M}}}{\mathrm{d} \tau}=C_{\mathrm{M} 0} \cdot \frac{\mathrm{d} X_{1}}{\mathrm{~d} \tau}=k_{\mathrm{pol}, 1} \cdot C_{\mathrm{M}} \cdot C_{\mathrm{I}}^{1 / 2} \\
& =k_{\mathrm{pol}, 1} \cdot C_{\mathrm{M} 0} \cdot\left(1-X_{1}\right) \cdot C_{\mathrm{I}}^{1 / 2}
\end{aligned}
$$

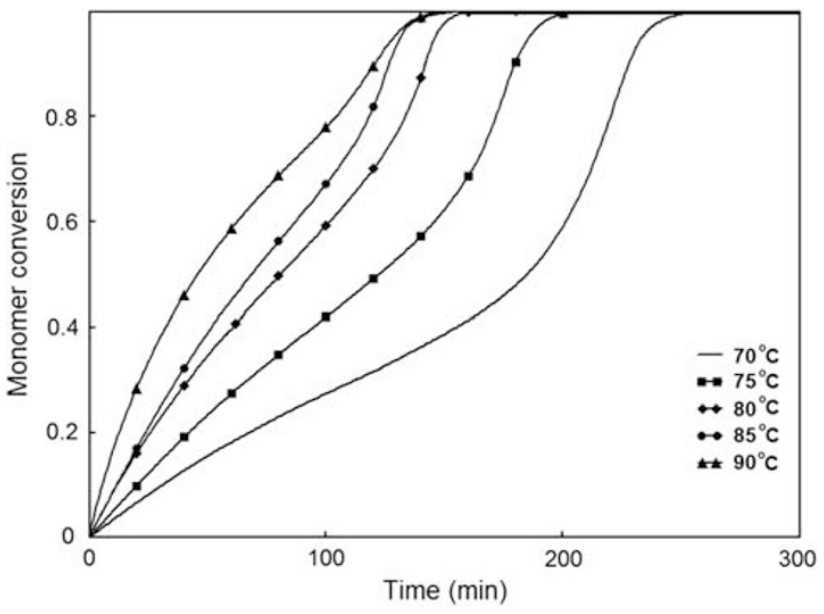

Figure 2 Styrene conversion vs time at different temperatures ( $1 \mathrm{wt} \% 2$, 2'-azobisisobutyronitrile). 


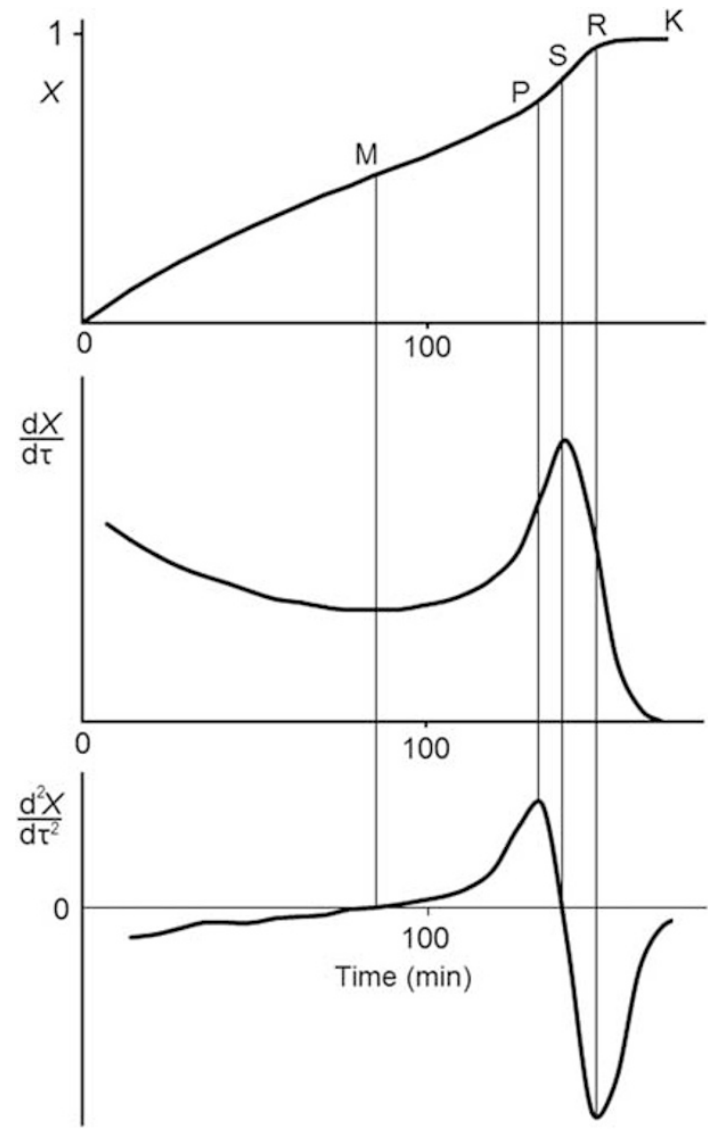

Figure 3 Characteristic points in the conversion $(X)$, rate of polymerization $(\mathrm{d} X / \mathrm{d} \tau)$ and acceleration $\left(\mathrm{d}^{2} X / \mathrm{d} \tau^{2}\right)$ vs time $(\tau)$ curves obtained by transformation of differential scanning calorimetry (DSC) curve of styrene polymerization at $80^{\circ} \mathrm{C}$ ( $1 \mathrm{wt} \% 2,2^{\prime}$-azobisisobutyronitrile).

Table 1 Time and styrene conversion, necessary to achieve characteristic points (determined from differential scanning calorimetry curves)

\begin{tabular}{lrrrrrrrr}
$\mathrm{T}\left({ }^{\circ} \mathrm{C}\right)$ & $\tau_{M}(\min )$ & $\mathrm{X}_{M}$ & $\tau_{P}(\min )$ & $\mathrm{X}_{P}$ & $\tau_{S}(\min )$ & $\mathrm{X}_{S}$ & $\tau_{R}(\min )$ & $\mathrm{X}_{R}$ \\
\hline 70 & 112 & 0.30 & 211 & 0.69 & 220 & 0.81 & 229 & 0.91 \\
75 & 91 & 0.39 & 167 & 0.75 & 174 & 0.84 & 181 & 0.91 \\
80 & 82 & 0.51 & 132 & 0.78 & 142 & 0.90 & 147 & 0.96 \\
85 & 84 & 0.58 & 119 & 0.81 & 125 & 0.88 & 132 & 0.96 \\
90 & 92 & 0.74 & 108 & 0.82 & 121 & 0.90 & 134 & 0.97 \\
\hline
\end{tabular}

Abbreviation: T, temperature.

Here, $X_{1}$ is the conversion of the part of the monomer that polymerizes according to the classical theory of polymerization; $k_{\text {pol, }, 1}$ is the corresponding polymerization rate constant; and $C_{\mathrm{I}}$ is the initiator concentration at time $\tau$.

It is usually supposed that there is a negligible change in initiator concentration during polymerization, that is, $C_{\mathrm{I}}=C_{\mathrm{I} 0}=$ constant. Hence, the rate of polymerization is described by equation (3)

$$
\frac{\mathrm{d} X_{1}}{\mathrm{~d} \tau}=k_{1} \cdot\left(1-X_{1}\right)
$$

where $k_{1}=k_{\mathrm{pol}, 1} C_{\mathrm{I}}^{1 / 2}$ is the rate constant for the first-order reaction.
Table 2 Values of parameters in equation (8) determined for styrenefree radical polymerization at different temperatures (obtained using method of least squares)

\begin{tabular}{lcccccc}
\hline $\mathrm{T}\left({ }^{\circ} \mathrm{C}\right)$ & $\mathrm{k}_{1} \times 10^{2}\left(\mathrm{~min}^{-1}\right)$ & $\mathrm{k}_{2} \times 10^{2}\left(\mathrm{~min}^{-1}\right)$ & $\mathrm{a}$ & $\tau_{2 \max }(\min )$ & s.d. ${ }^{\mathrm{a}}$ & $\mathrm{R}^{2 \mathrm{~b}}$ \\
\hline 70 & 1.193 & 6.114 & 0.599 & 203.9 & 0.029 & 0.992 \\
75 & 1.440 & 6.826 & 0.491 & 156.9 & 0.031 & 0.991 \\
80 & 1.954 & 7.274 & 0.428 & 120.7 & 0.029 & 0.992 \\
85 & 2.204 & 7.014 & 0.433 & 104.9 & 0.029 & 0.992 \\
90 & 2.534 & 7.982 & 0.265 & 104.5 & 0.014 & 0.998 \\
\hline
\end{tabular}

Abbreviation: T, temperature.

aStandard deviation (s.d.) of the residuals.

${ }^{b}$ Coefficient of determination.

All theories of rate polymerization autoacceleration assume that the polymer produced during the autoacceleration stage has a catalytical effect on polymerization. Hence, we propose that in that stage, the rate of polymerization depends on both the concentration of residual monomer $\mathrm{M}$ and the amount of created polymer $\mathrm{P}$, that is, equation (4). This equation can be easily transformed to equation (5).

$$
\begin{aligned}
& R_{\mathrm{pol}}=C_{\mathrm{M} 0} \cdot \frac{\mathrm{d} X_{2}}{\mathrm{~d} \tau}=k_{\mathrm{pol}, 2} \cdot C_{\mathrm{M}} \cdot C_{\mathrm{P}} \cdot C_{\mathrm{I}}^{1 / 2} \\
& \frac{\mathrm{d} X_{2}}{\mathrm{~d} \tau}=k_{2} \cdot X_{2} \cdot\left(1-X_{2}\right)
\end{aligned}
$$

where $X_{2}$ is conversion of a part of monomer that polymerizes according to the autoacceleration and deceleration mechanisms of polymerization, and $k_{2}=k_{\mathrm{pol}, 2} C_{\mathrm{M} 0} C_{\mathrm{I}}^{1 / 2}$ is the corresponding polymerization rate constant.

It should be noted that equation (5) is a parabola that has a maximum polymerization rate. Hence, it can be used to describe both the autoacceleration and the deceleration parts of the polymerization rate vs time curves.

After integrating and rearranging, equations (3) and (5) become equations (6) and (7):

$$
\begin{aligned}
& X_{1}(\tau)=1-\mathrm{e}^{-k_{1} \tau} \\
& X_{2}(\tau)=\frac{1}{\left.1+\mathrm{e}^{-k_{2}\left(\tau-\tau_{2} \max \right.}\right)}
\end{aligned}
$$

where $\tau_{2 \max }$ is the time necessary to achieve the maximum rate of autoacceleration stage equations (6) and (7) are conversions according to classical first-order polymerization and acceleration, respectively. At the end of polymerization, the achieved final conversion $X_{\mathrm{K}}$ consists of two fractions: $a$ is the monomer fraction polymerized by autoacceleration (that is, equation (7)) and $\left(X_{K}-a\right)$ is the monomer fraction polymerized by the first-order reaction (that is, equation (6)). $X_{\mathrm{K}}$ was very close to 1 in all of our experiments. On the basis of these assumptions, the dependence of the conversion on time can be presented by a mathematical model (equation (8)). The first addend corresponds to the first-order reaction and the second to autoacceleration. The model includes these two processes because they are not strictly separated, occurring simultaneously as two parallel reactions.

$$
X(\tau)=(1-a) \cdot\left(1-e^{-k_{1} \tau}\right)+\frac{a}{1+\mathrm{e}^{-k_{2}\left(\tau-\tau_{2 \max }\right)}}
$$




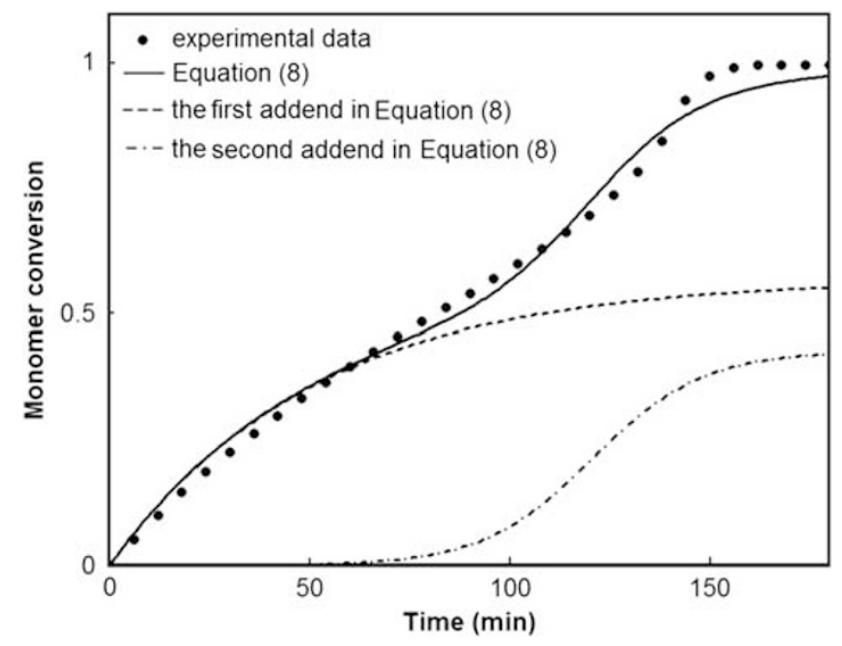

Figure 4 Styrene conversion vs time at $80^{\circ} \mathrm{C}$ ( 1 wt $\% \quad 2,2^{\prime}$ azobisisobutyronitrile).

In equation (8), values for $X$ and $\tau$ were obtained from experimental DSC data, whereas $k_{1}, k_{2}, a$ and $\tau_{2 \max }$ were calculated using the leastsquares method. The values of all calculated parameters are given in Table 2. The dependence of the degree of monomer conversion on polymerization time is well described by the estimated mathematical model given in equation (8) (Figure 4). The low values for standard deviation of the residuals and the high determination coefficients (Table 2) confirm this conclusion.

Although the model includes both addends from the beginning to the end of polymerization, the first addend dominates in the first part of conversion vs time curves (Figure 4). The contribution of the second addend, that is, polymerization acceleration, to the conversion is negligible in the first part, appears after some time, increases and becomes dominant in the second part of the polymerization.

Conversion $(X)$, rate of polymerization $(\mathrm{d} X / \mathrm{d} \tau)$ and acceleration $\left(\mathrm{d}^{2} X / \mathrm{d} \tau^{2}\right)$ vs time $(\tau)$ curves obtained by our mathematical model (Figure 5) have the same trends as the experimentally obtained curves (Figure 3).

After the determination of rate constants $\left(k_{1}\right.$ and $\left.k_{2}\right)$ at different temperatures, it is possible to calculate apparent activation energies using the Arrhenius equation. The dependences of the natural logarithm of the two reaction rate constants on the reciprocal temperature are presented in Figures 6 and 7. Apparent activation energies for the first-order reaction $\left(E_{a 1}\right)$ and autoacceleration $\left(E_{a 2}\right)$ are 40.1 and $11.6 \mathrm{~kJ} \mathrm{~mol}^{-1}$, respectively. The autoacceleration activation energy is approximately four times lower than the energy of the first-order reaction.

The value of parameter $a$ (Table 2 ) is very important because it is a monomer fraction reacted by autoacceleration. This value can take values between 0 and $1(0 \leqslant a \leqslant 1)$. If $a=0$, all of the monomer will react by first-order reaction only. On the other hand, if $a=1$, polymerization is described by autoacceleration only. Parameter $a$ is linearly dependent on the reaction temperature, and by extrapolating the fitted line, it is possible to obtain characteristic temperatures at which $a=0$ and $a=1$ (Figure 8).

As shown in Figure 8, the first-order reaction followed by autoacceleration takes place only between 41.7 and $110.5^{\circ} \mathrm{C}$. Below $41.7^{\circ} \mathrm{C}$, styrene reacts only by autoacceleration and above $110.5^{\circ} \mathrm{C}$,

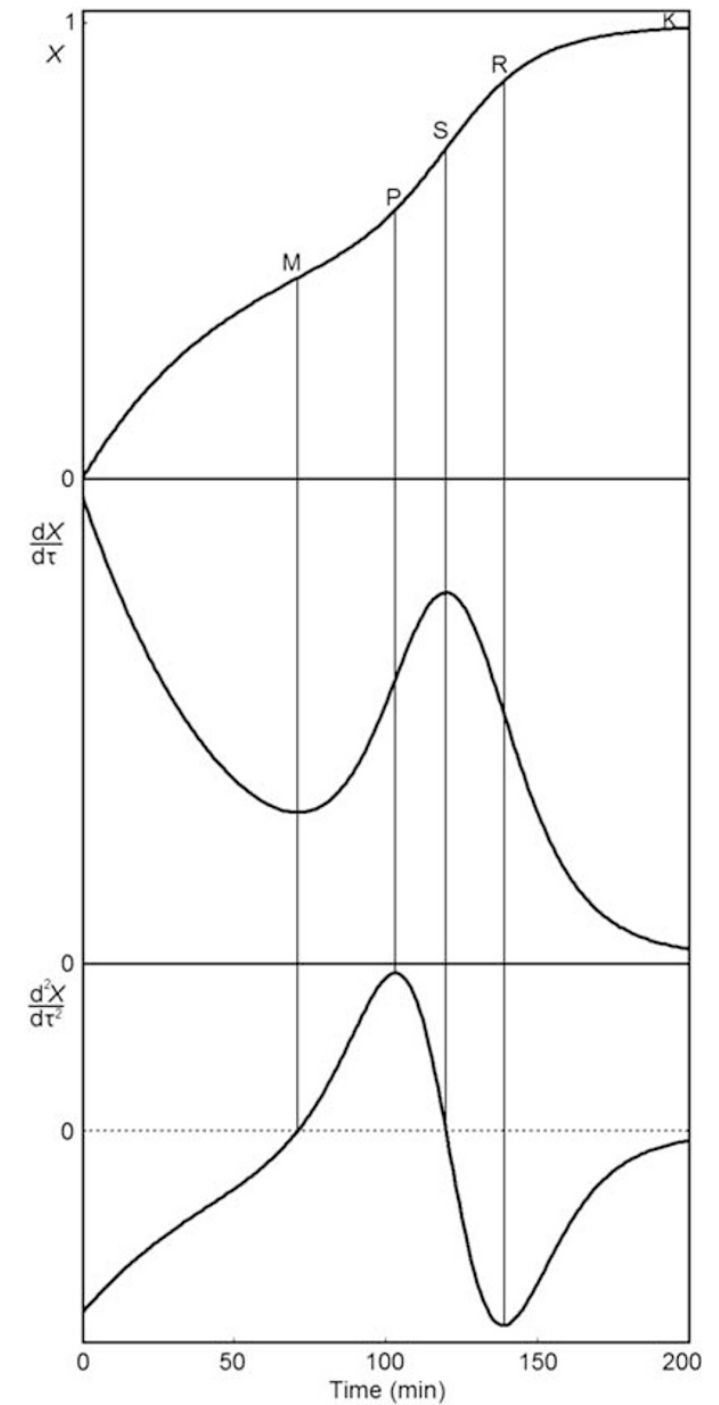

Figure 5 Conversion $(X)$, rate of polymerization $(\mathrm{d} X / \mathrm{d} \tau)$ and acceleration $\left(d^{2} X / d \tau^{2}\right)$ vs time.

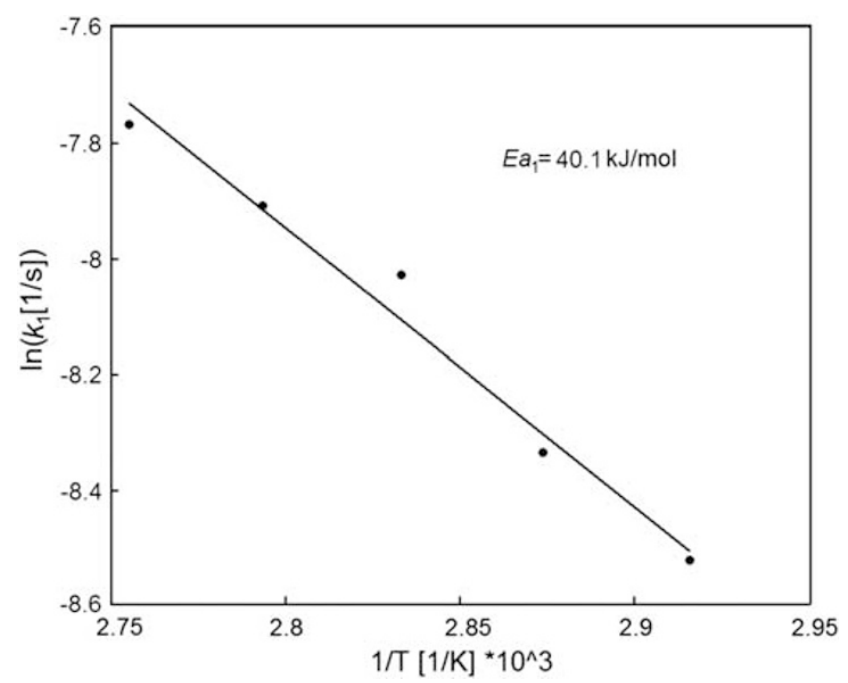

Figure 6 Dependence of $\ln \left(k_{1}\right)$ on reciprocal temperature for styrene polymerization (1 wt\% 2,2'-azobisisobutyronitrile). 


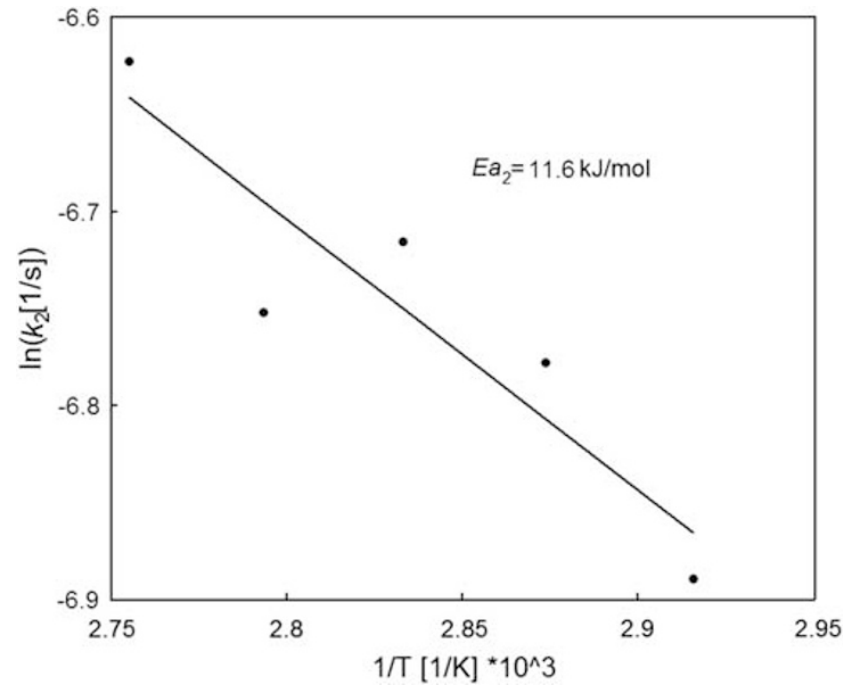

Figure 7 Dependence of $\ln \left(k_{2}\right)$ on reciprocal temperature for styrene polymerization (1 wt\% 2,2'-azobisisobutyronitrile).

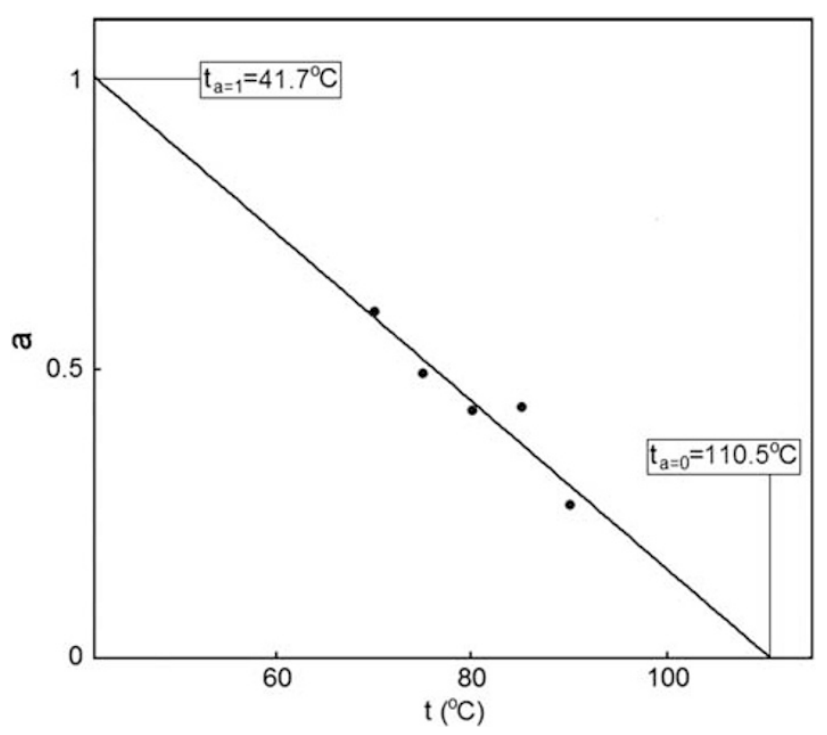

Figure 8 Dependence of parameter ' $a$ ' on temperature for styrene polymerization (1 wt\% 2,2'-azobisisobutyronitrile).

only by first-order law. The predicted temperatures are very close to the experimental values presented in the literature. ${ }^{1,3,8}$

Once the boundary temperatures were found, equation (8) could be rewritten more precisely, depending on the temperature range:

$$
\begin{aligned}
& X(\tau)=\frac{1}{\left.1+\mathrm{e}^{-k_{2}\left(\tau-\tau_{\mathrm{s}}\right.}\right)}, t \leqslant t_{a=1}\left(41.7^{\circ} \mathrm{C}\right) \\
& X(\tau)=(1-a) \cdot\left(1-\mathrm{e}^{-k_{1} \tau}\right) \\
& +\frac{a}{1+\mathrm{e}^{-k_{2}\left(\tau-\tau_{s}\right)}}, t_{a=1}\left(41.7^{\circ} \mathrm{C}\right) \leqslant t \leqslant t_{a=0}\left(110.5^{\circ} \mathrm{C}\right) \\
& X(\tau)=\left(1-\mathrm{e}^{-k_{1} \tau}\right), t \geqslant t_{a=0}\left(110.5^{\circ} \mathrm{C}\right)
\end{aligned}
$$

\section{CONCLUSIONS}

The following remarks were made:

- The polymerization of styrene shows the same characteristic points as polymerization of alkyl methacrylates: ${ }^{4,5}$ onset of autoacceleration (M), maximum autoacceleration (P) and maximum polymerization rate $(S)$, proceeded by deceleration stage with minimum (R) and final conversion (K).

- A new kinetic model of styrene-free radical bulk polymerization was developed. Experimental data of the dependence of styrene conversion on reaction time are well described by the estimated kinetic model.

- Autoacceleration activation energy is approximately four times lower than the energy of the first-order reaction.

- The first-order reaction and autoacceleration of styrene-free radical bulk polymerization occurs simultaneously between 41.7 and $110.5^{\circ} \mathrm{C}$. Below $41.7^{\circ} \mathrm{C}$, styrene reacts only by autoacceleration and above $110.5^{\circ} \mathrm{C}$ only by first-order low.

\section{ACKNOWLEDGEMENTS}

We express our gratitude to the Ministry of Science and Technological Development of the Republic of Serbia for providing financial support for this study (Project No. 45022).

1 Radičević, R., Kisin, S. \& Krakovsky, I. Analysis of the molecular weight distribution of polystyrene. Chromatographia. 59, 621-624 (2004).

2 Tefera, N., Weickert, G. \& Westerterp, K. R. Modeling of free radical polymerization up to high conversion. I. A method for the selection of models by simultaneous parameter estimation. J. Appl. Polym. Sci. 63, 1649-1661 (1997).

3 Ebdon, J. \& Hunt, B. Study of the free-radical polymerization of styrene by differential scanning calorimetry. Anal. Chem. 45, 804-806 (1973).

4 Radičević, R., Korugić, L.j., Stoiljković, D. \& Jovanović, S. Supermolecular organization and characteristic moments of the polymerization of methyl methacrylate. J. Serb. Chem. Soc. 60, 347-363 (1995).

5 Radičević, R., Stoiljković, D. \& Budinski-Simendić, J. Characteristic events in free radical polymerization of lower n-alkyl methacrylates. J. Therm. Anal. Cal. 62, 237-249 (2000).

6 Balke, S. T. \& Hamielec, A. E. Bulk polymerization of methyl methacrylate. J. App. Polym. Sci. 17, 905-949 (1973).

7 Stickler, M. Free-radical polymerization kinetics of methyl methacrylate at very high conversions. Makromol. Chem. 184, 2563-2579 (1983).

8 Ito, K. Auto-acceleration of radical polymerization rate in polymerization of styrene under the condition of predominant transfer. Eur. Polym. J. 23, 409-413 (1987).

9 Chekal, B. P. \& Torkelson, J. M. The strength of the gel effect in free radical polymerization: interplay of polymer physics and chain transfer. Anual March Meeting, American Physical Society, Minneapolis, MN, 20-24 March 2000 [abstract\#A22.010].

10 Cioffi, M., Ganzeveld, K. J., Hoffmann, A. C. \& Janssen, L.P.B.M. A rheokinetic study of bulk free radical polymerization performed with a helical barrel rheometer. Polym. Eng. Sci. 44, 179-185 (2004).

11 Frounchi, M., Farhadi, F. \& Pourdarvish Mohammadi, R. [Simulation of styrene radical polyneriyation in batch reactor: a modified kinetic model for high conversion]. Scientia Iranica 9, 86-92 (2002).

12 Kotoulas, C., Krallis, A., Pladis, P. \& Kiparissides, C. A comprehensive kinetic model for the combined chemical and thermal polymerization of styrene up to high conversions. Macromol. Chem. Phys. 204, 1305-1314 (2003).

13 Almeida, A. S., Wada, K. \& Secchi, A. R. Simulation of styrene polymerization reactors: kinetic and thermodynamic modeling. Braz. J. Chem. Eng. 25, 337-349 (2008).

14 Trommsdorff, E., Köhle, H. \& Lagally, P. [Zur polymerisation des methacrylsauremethylesters]. Makromol. Chem. 1, 168-198 (1947).

15 Kuo, J. F. \& Chen, C. Y. Studies on the radical chain copolymerization of methyl methacrylate and styrene at their azeotropic composition. Macromolecules 14, 335-339 (1981).

16 Litvinenko, G. I., Lachinov, M. B., Sarkisova, E. V. \& Kaminskii, V. A. On the gel effect in free-radical polymerization of styrene. Polym. J. 36, 270-275 (1994).

17 High, K. A., Lee, H. B. \& Turner, D. T. Autoacceleration of free-radical polymerization. 4. Predissolved polymer. Macromolecules 12, 332-337 (1979).

18 O'Driscoll, K. F., Dionision, J. M. \& Mahabadi, H.Kh. The temperature dependence of the gel effect in free-radical vinyl polymerization. Am. Chem. Soc. Symp. 104, 361-374 (1979). 
19 Lachinov, M. B., Simonian, R. A., Georgieva, T. G., Zubov, V. P. \& Kabanov, V. A. Nature of gel effect in radical polymerization. J. Polym. Sci. Pol. Chem. 17, 613-616 (1979).

20 Arai, K. \& Saito, S. Simulation model for the rate of bulk polymerization over. The complete course of reaction. J. Chem. Eng. Japan 9, 302-313 (1976).

21 Turner, D. T. Autoacceleration of free-radical polymerization. 1. The critical concentration. Macromolecules 10, 221-226 (1977).

22 Kargin, V. A. \& Kabanov, V. [Polymerization in cross-linked systems]. Zh. Vses., Khim. Ob. im. D. I. Mendeleeva 9, 602-621 (1964).

23 Radičević, R., Stoiljković, D. \& Sinadinović-Fišer, S. [Free radical polymerization of vinyl monomers]. Acta Periodica Technologica 28, 83-93 (1997).
24 Jašo, V., Radićević, R. \& Stoiljković, D. Analysis of DSC curve of dodecyl methacrylate polymerization by two-peak deconvolution method. J. Term. Anal. Calorim. 101, 1059-1063 (2010).

25 Radičević, R., Stoiljković, D. \& Budinski-Simendić, J. Study of the isothermal free radical polymerization of some higher n-alkyl methacrylates. J. Therm. Anal. Cal. 90, 243-247 (2007).

26 Jovičić, M., Radičević, R. \& Budinski-Simendić, J. Curing of alkyds based on semidrying oils with melamine resin. J. Therm. Anal. Cal. 94, 143-150 (2008).

27 Joshi, M. V. \& Mukesh, D. Experimental and modelling studies on styrene butyl methacrylate copolmerization reaction. J. Appl. Polym. Sci. 50, 75-81 (1993). 